\title{
Cardiovascular reactivity and burnout syndrome of medical personnel
}

\author{
Marina Chukhrova ${ }^{1, *}$, Sergey Pronin $^{1}$, Elena Schukina $^{2}$, Ekaterina Goncharova ${ }^{2}$, and \\ Vera Morozova $^{2}$ \\ ${ }^{1}$ Novosibirsk State University of Economics And Management (Nsuem), 52 Str. Kamenskaya, \\ 630099, Novosibirsk, Russia \\ ${ }^{3}$ Institute of Clinical Medicine named after N.V. Sklifosovsky, st. Bolshaya Pirogovskaya, 2, building \\ 4, office 106, 119991, Moscow, Russia
}

\begin{abstract}
Purpose of the study is to analyze the relationship between latent alcohol consumption, burnout syndrome and the cardiovascular system reactivity of nurses. It was shown that the total number of people with burnout syndrome revealed signs of systematic alcohol consumption significantly more often than without signs of EBS $(P=0.001)$. there were $8 \%$ of people in the first group and $23 \%$ of people in the second with a high probability of addiction to nicotine and coffee. In a group of people with a high level of alcohol consumption (from 2.6 to 9.9 drinks), a decrease in the adaptive potential of cardiovascular system was revealed in $45 \%$ of cases. The dose-dependent effects of alcohol togather with EBS are interrelated with the VLF index. At the same time, pearson's correlation of the VLF index (neuroendocrine component) with the amount of alcohol consumed was significant $r_{p}=0,291 ; P=0,05$ (double-sided). The lower activity of alcohol consumption was influenced by the marital status of the surveyed persons, regardless of the service length. It is concluded that alcohol has a negative effect on the cardiovascular system, which leads to a decrease in the professional suitability of medical personnel and a more pronounced burnout syndrome.
\end{abstract}

\section{Introduction}

The work of medical staff is associated with a high risk of the emotional burnout syndrome formation (EBS), which is expressed in cognitive, motivational, emotional disorders, dissatisfaction with oneself, decreased work productivity, and insensitivity to patients' problems $[1,2,3,4]$. Burnout syndrome is detected among medical staff in at least $30 \%$ of cases, although it should be noted that the diagnosis of this syndrome is subjective $[5,6]$, and due to methodological shortcomings of accounting does not reflect the real nature of this condition and its accompanying disorders. In particular, it does not reflect such serious psychosomatic conditions as latent alcoholism and cardiovascular pathology [7]. Emotional distress, dissatisfaction with oneself and one's work causes chronic emotional stress and an attempt to relieve this stress with the help of alcohol. There is a

*Corresponding author: michmacha@mail.ru 
need to increase attention to the problem of latent alcohol, nicotine and coffee consumption of the medical staff. Their work is associated with emotional and stressful loads, and, despite the fact that the medical staff undergoes systematic medical examination, they periodically reveal abnormalities from the cardiovascular system, which do not fit into the established diagnostic ideas about this pathology [7, 8]. In the of L.S. Fernandes studies, it was shown that 50 to $74 \%$ systematically took alcohol to relax out of 160 surveyed nurses who showed signs of emotional burnout [9]. There is a need to take into account the influence of various factors, including alcohol and other psychoactive substances (PS), which can increase the risk of burnout syndrome, and generally affect the professional suitability of medical staff. Alcohol and nicotine consumption can increase the risk of cardiovascular disease, and physicians are often not aware of the level of alcohol abuse. The need to objectify the state of medical staff and to clarify the role of alcohol consumption in relation to burnout syndrome is a our study problem.

\section{Materials and methods}

Purpose of the study is to analyze the relationship between latent alcohol consumption, burnout syndrome and the reactivity of the cardiovascular system of nurses.

Study design is solid, open-ended, prospective, non-randomized. The study was carried out in several large city hospitals in Novosibirsk, Magadan, Sakhalin. Questioning, survey and analysis of heart rate variability (HRV) according to electrocardiography testing were carried out among 329 women, mean age $(\mathrm{M} \pm \mathrm{SD}) 31.8 \pm 8.3$ years; informed consent was obtained to participate in the study (Table 1).

Table 1. Distribution of respondents and some demographic characteristics, depending on the region.

\begin{tabular}{|c|c|c|c|c|c|}
\hline Region & Hospital & $\mathbf{N}$ & В \% & $\begin{array}{c}\text { Number of } \\
\text { women \% (N) }\end{array}$ & $\begin{array}{l}\text { Average } \\
\text { number of } \\
\text { children } \\
(\mathrm{N}=\mathbf{2 4 2}) \\
\end{array}$ \\
\hline $\begin{array}{l}\text { Novosibirsk } \\
\text { region }\end{array}$ & $\begin{array}{l}\text { Novosibirsk, } \\
\text { regional hospital N } \\
25\end{array}$ & 176 & 51.9 & $96.5 \%$ (170) & $1.53 \pm 0.641$ \\
\hline \multirow[t]{3}{*}{$\begin{array}{l}\text { Magadan } \\
\text { Region }\end{array}$} & \begin{tabular}{|l|} 
Palatka \\
MRPABI \\
Khasynskaya \\
Central District \\
Hospital \\
\end{tabular} & 18 & 5.3 & & \\
\hline & $\begin{array}{l}\text { Magadan MABI } \\
\text { MOB }\end{array}$ & 44 & 13.0 & & \\
\hline & Всего & 62 & 18.3 & 95.2 & $1.75 \pm 0.959$ \\
\hline \multirow{4}{*}{$\begin{array}{l}\text { Sakhalin } \\
\text { Region }\end{array}$} & $\begin{array}{l}\text { Yuzhno- } \\
\text { Sakhalinsk SBI } \\
\text { named after. F.S. } \\
\text { Ankudinova }\end{array}$ & 5 & 1.5 & & \\
\hline & $\begin{array}{l}\text { Nogliki } \\
\text { SBI NTZDH }\end{array}$ & 48 & 14.2 & & \\
\hline & $\begin{array}{l}\text { Makarov } \\
\text { SBI MCDH } \\
\text { Sakhalin Region } \\
\end{array}$ & 48 & 14.2 & & \\
\hline & total & 101 & 29.9 & 93.1 & $1.83 \pm 0.935$ \\
\hline \multicolumn{2}{|l|}{ In total } & 339 & 100.0 & & $1.67 \pm 0.824$ \\
\hline
\end{tabular}

General demographic characteristics of the subjects. The questionnaire was distributed among 340 nurses in the regional hospital in Novosibirsk within two months (January- 
February 2018) and 176 questionnaires were returned, 4 people of junior medical staff (nurses and medical registrars) were excluded from the sample. The response was $50.2 \%$. The general demographic characteristics of nursing staff, where $98.8 \%$ of the sample are women $(\mathrm{N}=170)$ and there are two men are shown in the Table 1.63 people were interviewed (2019) in the hospitals of the Far East. The distribution by specialty were: Far East / Novosibirsk - 25.2 / 25.6\% guards, 3.7 / 16.1\% nurses (n) of specialized offices; 11.0 / 14.3\% other (catering, emergency room, etc.); 1.8 / 10.2\% precinct; 6.1 / 7.7\% procedural; 4.9 / 4.8\% sinior nurses; ward nurses -1.2 / 4.2\%; surgical - 10.4 / 3.6\%; midwives -3.7 / $3 \%$. Also the emergency paramedics participated in the survey, $8.6 \%$ and doctors $-9.2 \%$ (in Novosibirsk they were excluded from the study). Average number of children $(\mathrm{M}+/-\delta)$ $1.8 \pm 0.94 / 1,54 \pm 0.65$. The distribution according to the number of children: did not have 3.9 / 2.6; one - 35.2 / 47.0; two - 45.3 /44.3; three - 10.2 / 6.1; four or more - 5.5 / 0 . The distribution of respondents by age groups depending on the region are shown in Table 2.

Table 2. Comparison of the respondents distribution by age groups depending on the region $(\mathrm{N}=329)$.

\begin{tabular}{|c|c|c|c|c|c|c|}
\hline \multirow{3}{*}{ Age group } & \multicolumn{6}{|c|}{ Region } \\
\hline & \multicolumn{2}{|c|}{ Novosibirsk } & \multicolumn{2}{|c|}{$\begin{array}{c}\text { Magadan } \\
\text { Region }\end{array}$} & \multicolumn{2}{|c|}{ Sakhalin Region } \\
\hline & $\mathbf{N}$ & $\%$ & $\mathbf{N}$ & $\%$ & $\mathbf{N}$ & $\%$ \\
\hline $21-28$ & 27 & 15.8 & 19 & 30.6 & 21 & 21.4 \\
\hline $29-35$ & 23 & 13.5 & 2 & 3.2 & 1 & 1.0 \\
\hline $36-44$ & 33 & 19.3 & 13 & 21.0 & 30 & 30.6 \\
\hline $45-50$ & 23 & 13.5 & 9 & 14.5 & 15 & 15.3 \\
\hline $51-55$ & 35 & 20.5 & 6 & 9.7 & 10 & 10.2 \\
\hline $56-60$ & 17 & 9.9 & 7 & 11.3 & 8 & 8.2 \\
\hline$\geq 61$ & 13 & 7.6 & 6 & 9.7 & 13 & 13.3 \\
\hline Total & 172 & 100.0 & 62 & 100.0 & 98 & 100.0 \\
\hline
\end{tabular}

Research methods. The subjects were tested using the test "Diagnostics of the emotional burnout level by V.V. Boyko "[2] and divided into two groups depending on the presence of EBS: group 1, without EBS, $\mathrm{N}=148$ people (45\%), age $26.7 \pm 7.8$ years, and group 2, EBS was detected, $\mathrm{N}=181(55 \%)$, age $37.7 \pm 7.3$ years. Distribution by marital status in the first / second groups: single - 46.1\% / 4.9\% (average age - 24.2 years / 33.5 years) divorced $-4.6 \% / 4.3 \%$ (29.5 years / 28, 9 years), in a civil marriage $-7.7 \% / 5.3 \%(25.1$ years / 35.8 years).

The adaptive potential of the cardiovascular system was calculated from the data on the heart rate variability. The calculation of basic HRV indices was based on the method, described in articles and guidelines $[10,11,12]$. Currently, it is proposed to consider HRV as a transdiagnostic test; it is considered as a psychophysiological marker of general psychopathology [13]. Nowadays data available suggest, that changes in some of HRV components may be associated with the presence of alcohol dependence, depression, and suicidal dominance $[14,15]$.

As a part of the anamnesis collection, a test questionnaire was used, which contained 27 questions, included demographic characteristics, somatic complaints, sleep quality, mood, attitude to alcohol and nicotine consumption.

SPSS v22 was used for statistical data processing.

Methodology for assessing the level of alcohol consumption. CAGE test was used along with the DSM-IV and ICD-X criteria to assess the degree of alcohol consumption [16]. One conditional dose of alcohol (Drink) equals $50 \mathrm{ml}$ of $40 \%$ alcohol, or $200 \mathrm{ml}$ of wine or 500 $\mathrm{ml}$ of beer, and is considered relatively safe with a frequency of 2-3 times a month, based on the USDA / HHS Dietary Guidelines criteria. Previously, we identified reference points according to HRV electrocardiogram data of persons with confirmed alcohol dependence 
[8], which use allowed us to identify the likelihood of systematic alcohol consumption, using logistic regression analysis (see Table 3, Table 4).

Table 3. Distribution of alcohol consumption frequency in the past month before the survey.

\begin{tabular}{|l|c|c|c|c|c|c|c|}
\hline \multirow{2}{*}{$\begin{array}{c}\text { Alcohol intake } \\
\text { in the past } \\
\text { month }\end{array}$} & \multicolumn{4}{|c|}{ EBS } & \multicolumn{4}{c|}{ Total } \\
\cline { 2 - 8 } & $\mathbf{N}$ & $\mathbf{N}$ by line & $\mathbf{N}$ & $\begin{array}{c}\text { Y\% by } \\
\text { line }\end{array}$ & $\mathbf{N}$ & $\begin{array}{c}\text { \% by } \\
\text { colum } \\
\mathbf{n}\end{array}$ & $\begin{array}{c}\% \text { by } \\
\text { line }\end{array}$ \\
\hline not & 49 & $52 \%$ & 46 & $48 \%$ & 95 & $28 \%$ & $100 \%$ \\
\hline $\begin{array}{l}1-3 \text { times a } \\
\text { month }\end{array}$ & 85 & $47 \%$ & 97 & $53 \%$ & 182 & $53 \%$ & $100 \%$ \\
\hline $2-3$ times a week & 14 & $27 \%$ & 38 & $73 \%$ & 51 & $15 \%$ & $100 \%$ \\
\hline total & 148 & $45 \%$ & 181 & $55 \%$ & 329 & $100 \%$ & $100 \%$ \\
\hline
\end{tabular}

Table 4. Do you think that alcohol can sometimes be used to relax? (N=339) (in \%).

\begin{tabular}{|l|c|c|c|}
\hline \multirow{2}{*}{} & \multicolumn{3}{|c|}{ Region } \\
\cline { 2 - 4 } & Novosibirsk & Magadan Region & in small doses \\
\hline $\begin{array}{l}\text { Yes, it is safe in in small doses } \\
\text { and only 1-3 times a month }\end{array}$ & 12.7 & 19.7 & 32.7 \\
\hline once a week & 6.4 & 9.8 & 5.1 \\
\hline 2-3 times a week & 1.2 & 3.3 & 1.0 \\
\hline $\begin{array}{l}\text { In general, they are ready to take } \\
\text { alcohol (sum of data for lines 1 } \\
2+3)\end{array}$ & 20.3 & 32.8 & 38.8 \\
\hline $\begin{array}{l}\text { Drinking alcohol will still not } \\
\text { help and will only worsen the } \\
\text { condition. }\end{array}$ & 66.5 & 47.5 & 48.0 \\
\hline $\begin{array}{l}\text { Difficult to answer } \\
\text { Total }\end{array}$ & 13.3 & 19.7 & 13.3 \\
\hline
\end{tabular}

\section{Resuits}

In the surveyed sample, the dose of alcohol in conventional units (drinks) in the case of its intake was on average 3.3 c.u. / day (12.7 cigarettes / day) in group 1 and 3.7 c.u. / day, (10.3 cigarettes / day) in the second group. At the same time, $28 \%$ completely denied taking alcohol over the past month (group $1-31 \%$ / group $2-29 \%$ ). The following gradations were used to form comparison groups, depending on the frequency and amount of alcohol consumed: "controlling" 1-2 drinks / day with a frequency of 1-3 times / month: $53 \%$ of the surveyed were assigned (54\% / 60\%). "Moderate" - 2 - 3 times a week and $4-5$ drinks per reception - 15\% (8\% / 23\%). "High-risk" people who took more than 5 drinks per day every day $-4 \%(6 \% / 2 \%)$. The intensity of nicotine and alcohol consumption, depending on the presence or absence of EBS is shown in Table 5.

Table 5. Intensity of nicotine, alcohol consumption and EBS $(\mathrm{N}=329)$.

\begin{tabular}{|l|c|c|c|c|}
\hline \multirow{2}{*}{$\begin{array}{c}\text { Alcohol intake in the past } \\
\text { month }\end{array}$} & \multicolumn{2}{|c|}{$\begin{array}{c}\text { Number of smoked cigarettes } \\
\text { per day (pieces) }\end{array}$} & \multicolumn{2}{c|}{$\begin{array}{c}\text { Alcohol dose in conv. units } \\
\text { per day }\end{array}$} \\
\cline { 2 - 5 } & $\begin{array}{c}\text { EBS was not } \\
\text { identified }\end{array}$ & $\begin{array}{c}\text { EBS was } \\
\text { identified }\end{array}$ & $\begin{array}{c}\text { EBS was not } \\
\text { identified }\end{array}$ & $\begin{array}{c}\text { EBS was not } \\
\text { identified }\end{array}$ \\
\hline Not & 6 & 11 & -- & -- \\
\hline $1-3$ times a month & 13 & 12 & 3 & 3 \\
\hline $2-3$ times a week & 8 & 13 & 2 & 4 \\
\hline everyday & 13 & -- & 4 & -- \\
\hline
\end{tabular}




\begin{tabular}{|l|c|c|c|c|}
\hline Average value & 10 & 9 & 2.25 & 1.75 \\
\hline
\end{tabular}

Indicators of central hemodynamics (CHD) and heart rate variability (HRV). Indicators of central hemodynamics according to electrocardiogram recording heart rate $=71 \pm 12$ beats in min. Kerdo index $=-3.5 \pm 16.2$ conv. units There were no differences in these indicators and in the group of alcohol consumption, work experience $(\mathrm{F}=0.322 ; \mathrm{P}=$ $0,809)$. The decrease in alcohol consumption activity was influenced by the marital status of the surveyed people, regardless of the service length.

The high-frequency component of HRV (HF, respiratory arrhythmia), depending on EBS no / yes, was 44\% / 37\% (the influence of alcohol was excluded). The slow component of HRV - LF changed insignificantly 38\% / 36\%. And very slowly, the wave activity of HRV (VLF) increased 18\% / 27\%. Dose-dependent effects of alcohol " EBS no" are interrelated with the VLF index. At the same time, Pearson's correlation of the VLF index (neuroendocrine component) with the amount of alcohol consumed was significant $r_{p}$ $=0,236 \div 0,254(\mathrm{P}=0,05)$ (double-sided). With EBS there was only a significant correlation $\mathrm{r}_{\mathrm{p}}=0,344 ; \mathrm{P}=0,05$ (two-sided) with an increase in the LF index (slow-wave activity, vascular component) and with the amount of alcohol consumed.

The number of smoked cigarettes only in the first group directly correlated with the dose of alcohol and vascular reactions. Thus, the correlation of the LF index with the dose of alcohol was $r_{p}=0,344 ; P=0,05$ regardless of EBS. BPD increase is also directly related to the amount of alcohol consumed.

The analysis of the dominant type of cardiovascular system regulation is carried out. It was revealed that the dominant type of regulation is vagotonic in $54 \div 73 \%$ of individuals in the surveyed contingent, who reflects the state of functional tension of a body homeostatic activity and it has a predisposing effect on metabolic disorders (atherosclerosis, obesity).

Assessment of the autonomic nervous system activity. Comparative assessment by groups of abstinent / controlling / moderate / high-risk according to the Kerdo index, the following distribution was noted - normotonia was noted in $3.6 \% / 1.9 \% / 0 \% / 0 \%$; vagotonia was noted in 53.6\% / 59.6\% / 73.3\% / 33.3\%; sympathicotonia was noted in $42.9 \% / 38.5 \% / 26.7 \% / 66.7 \%$.

\section{Discussion}

According to dispensary testing of medical staff, the frequency of consumption and the amount of alcohol consumed over the past month, on average, exceeds the safe range of WHO norm. Groups are identified that already have certain clinical manifestations of alcohol dependence (CAGE test) and their total number can reach 19\%. It is generally believed that an increased risk of alcohol-related problems is observed among men who consume more than 5 drinks per day or $>15$ drinks in week. 4 drinks a day or more than 8 drinks a week were for women. Therefore, the number of persons assigned to the group of probable alcohol dependence may increase to $23 \%$, using more "stringent" criteria for assessing dependence.

The analysis of heart rate variability revealed that high-risk alcohol consumption, which was 2.7 times higher in relation to other groups, correlated with a decrease and a sharp decrease in the potential of the cardiovascular system. A sharp decrease was observed among people of group 2 (9.9 drinks), and among people of group 1 ( 8.8 drinks). The relationship between a decrease and a sharp decrease in the adaptive potential of the cardiovascular system with a high level of alcohol consumption (from 2.6 - 3.5 to 9.9 drinks) was revealed in $45 \%$ of cases (see Fig. 1). 


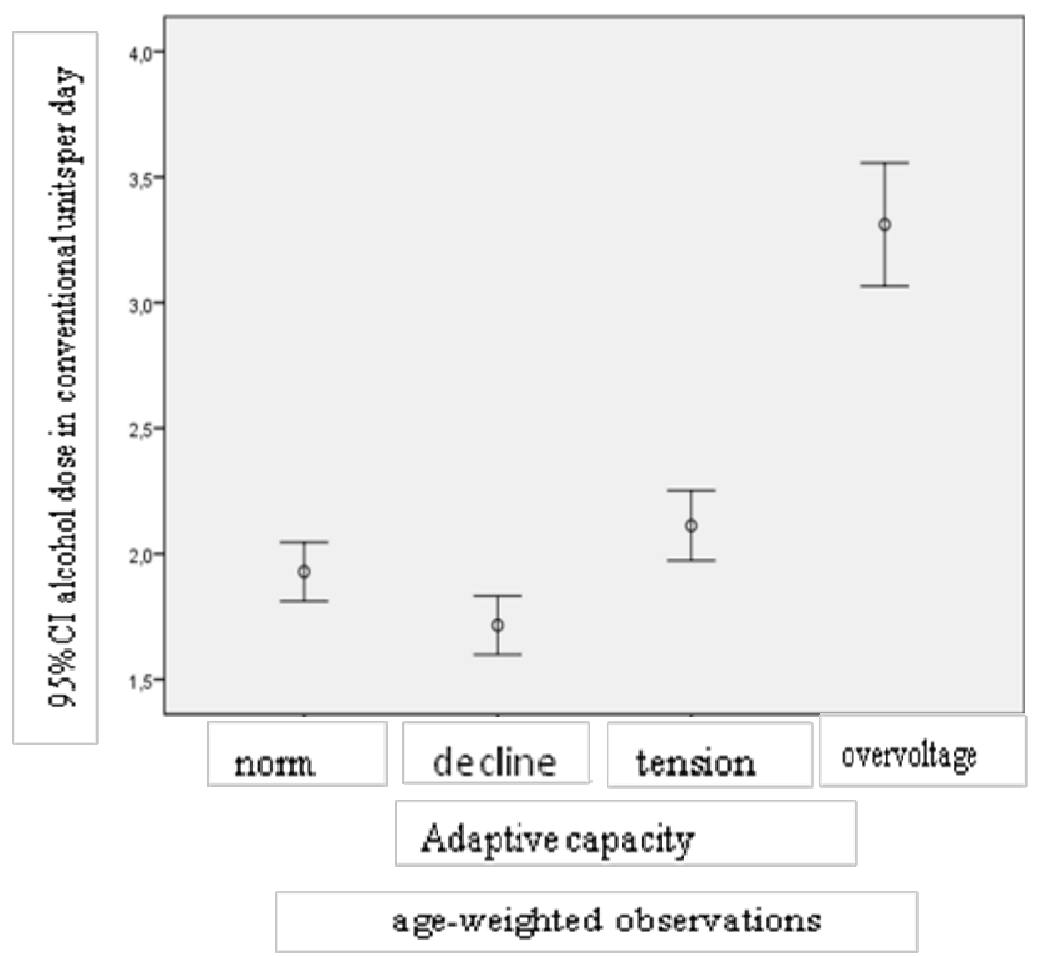

Fig. 1. The relationship between the adaptive potential of cardiovascular system and the alcohol consumption level $(\mathrm{N}=99)$.

Thus, a relationship was revealed between alcohol consumption, burnout syndrome, and a decrease in the adaptive potential of the cardiovascular system of nurses in some Russian hospitals. At the same time, the total number of people with an initial or established dependence on alcohol can reach $23 \%$, which will affect the cardiovascular system, leading to a decrease in the level of professional suitability to a certain extent. It is noted that in the moderate-risk group there is a high probability of a sharp decrease in the adaptive potential of the cardiovascular system, which necessitates medical corrective measures. In this case, people, assigned to the groups "moderately - high risk" for alcohol, often turn to doctors for various reasons, but the deterioration of their general somatic state in association with alcohol intake is not taken into account. This does not improve the medical correction efficiency of painful conditions. Of course, the study scope is always limited by multifactorial assessment possibility of lifestyle effect and other factors on the state of the cardiovascular system. This influence on the results study of possible random factors was partially corrected by including weighing variables - age, length of service, marital status, physical activity, body weight, degree of dependence on alcohol and nicotine, as well as taking into account a number of other factors.

The relationship between burnout syndrome, alcohol consumption and dysfunctions of the cardiovascular system among the medical staff in the city hospitals has been established. This leads to a decrease in adaptive capacity and increases the risk of cardiovascular diseases, as well as leads to a decrease in professionalism. Perhaps the time has come to state the fact that even small doses of alcohol can be harmful to health, especially since this message is important for medical workers. It is necessary to actively carry out preventive measures that form a negative attitude towards psychoactive substances (alcohol, nicotine, etc.). It is also important for doctors to overcome the peculiar diagnostic "anosognosia" of alcoholic lesions of the cardiovascular system and the possible 
relationship of impaired somatic functions with the consequences of alcohol and other surfactants (nicotine, coffee).

\section{Acknowledgements}

The authors confirm that there is no conflict of interest in the preparation of this article.

\section{References}

1. N.N. Sudilovskaya, A.M. Khizmatulina, International Journal of Experimental Education, Smolensk (2017)

2. N.E.Vodopyanova, E.S. Starchenkova Burnout syndrome: diagnosis and prevention, 2th ed. (Peter, SPb, 2008)

3. V.A. Ivanchenko, Science Time 1(13), 162-166 (2015)

4. O.S. Popova, Postgraduate student 52(10), 23-24 (2015)

5. C. Maslach, Journal of Applied Psychology 93(3), 498-512 (2008)

6. R. Lee, Journal of Organizational Behavior 14, 3-20 (1993)

7. O. Yuguero, J. Ramon Marsal, M. Esquerda, J. Soler-Gonzalez, BMC Fam Pract, 18 63 (2017) doi: 10.1186/s12875-017-0634-0

8. S.V. Pronin, M.G. Chukhrova, L.S. Egorova, Psychosomatics in clinical practice (Publishing House LLC "Nemo Press", Novosibirsk, 2019)

9. L.S. Fernandes, M.J.T. Nitsche, M. de Godoy, Ciencia \& Saude Coletiva 23(1), 203214 (2018) DOI: 10.1590 / 1413-81232018231.05612015

10. B.M. Appelhans, L.J. Luecken, Review of General Psychology 10, 229-240 (2006) https:.doi.org/10.1037/1089-2680.10.3.229

11. Heart rate variability. Europ Heart 17, 354-381 (1996)

12. R.M. Baevsky, G.G. Ivanov, L.V. Chireikin et al., Arrhythmology Bulletin 24, 65-87 (2001)

13. T.P. Beauchaine, J.F. Thayer, Int. J. Psychophysiol 98(2Pt2), 338-350 (2015) doi: 10.1016/j.ijpsycho.2015.08.004

14. A.H. Khandoker, V. Luthra, Y. Abouallaban et al., Med. Biol. Eng. Comput. (2016) doi:10.1007/s11517-016-1557-y

15. S.V. Pronin, M.G. Chukhrova, Suicidology 9(4), 109-117 (2018) Doi.org/10.32878/suiciderus.18-09-04(33)-109-117

16. J.A. Ewing, JAMA 14, 1905-1907 (1984) 